\title{
Glutamine synthetase activity during embryonic and larval development of the silkworm Bombyx mori L. and role of a $\mathrm{JH}$ analogue
}

\author{
R. V. SESHACHALAM, M. V. V. SUBRAMANYAM* and \\ R. V. KRISHNAMOORTHY ${ }^{\dagger}$ Department of Zoology, M.E.S. College, Bangalore, \\ *Department of Sericulture, Bangalore University, Bangalore, and ${ }^{\dagger}$ Department of Zoology, G.K.V.K. Campus, \\ University of Agricultural Sciences, Bangalore, India
}

\begin{abstract}
Silkworm eggs of diapause nature were chilled or treated with hydrochloric acid. Glutamine synthetase activity in such treated eggs was present soon after the treatment, whereas in non-diapause eggs it was not detectable until $24 \mathrm{~h}$ after the start of development. During larval life, the glutamine synthetase was found to be absent in midgut tissue. Topical application of a JH analogue resulted in extened larval duration and it reduced glutamine synthetase activity initially, but in the latter part of development the activity was higher.
\end{abstract}

Key words. Bombyx mori, glutamine synthetase, diapause, topical application, $\mathrm{JH}$ analogue.

\section{Introduction}

Glutamine plays a major role in the metabolism of nitrogen containing organic compounds. It donates its amide group to various compounds such as nucleic acids, histidine, tryptophan, carbamyl phosphate, glucosamine (Stadtman, 1973) and also involved in uric acid formation. In silkworm larvae, at the beginning of the fifth stadium the concentration of glutamic acid is highest (Fukuda et al., 1961) and the presence of glutamic acid and aspartic acid as amides in the haemolymph of silkworm suggests the presence of their synthetase in tissues. These two amino acids levels also vary during larval life (Gamo \& Kuroda, 1978) and, as reported, they play a key role as reservoirs of transferable amino groups (Gilmour, 1965).

Initiation and termination of diapause influences amino acid levels including glutamine in diapausing insects (MacFarlane \& Hogan, 1966; Mansing, 1967; Osanai \& Yonezawa, 1986; Storey et al., 1981). Excess of glutamine or glutamate in insect haemolymph during metamorphosis (Lennie \& Birt, 1965; Levenbook, 1962) and increase in glutamine levels in contrast to glutamic acid during embryonic diapause of Drosophila melanogaster (Crone-Gloor, 1959) denotes the involvement of glutamine synthetase.

The above observations prompted us to consider the variations in glutamine synthetase activity to obtain a

Correspondence: Dr M. V. V. Subramanyam, Department of Sericulture, Bangalore University, P.K. Block, Bangalore 560009 , India. better understanding of its physiological role in embryonic larval and extended larval periods of silkworms.

\section{Materials and Methods}

Bivoltine $\left(\mathrm{NB}_{18}\right)$ and multivoltine (pure Mysore) races of silkworm Bombyx mori L. were maintained under standard conditions $\left(25 \pm 2^{\circ} \mathrm{C}\right)$ and $75 \%$ r.h. on mulberry leaf of $\mathbf{M}_{5}$ variety. Eggs laid on polythene sheets were kept at $25 \pm 2{ }^{\circ} \mathrm{C}$ with a relative humidity of $80 \%$. For breaking diapause, 20-h-old eggs were treated with $\mathrm{HCl}$ (specific gravity 1.075 ) at $46^{\circ} \mathrm{C}$ for $3-4 \mathrm{~min}$, washed throughly in running water and incubated at $25 \pm 2^{\circ} \mathrm{C}$. In an artificial chilling process the diapause eggs were chilled according to Ullal \& Narasimhanna (1981) by gradually transferring them to $15^{\circ} \mathrm{C}$ (for 5 days), $10^{\circ} \mathrm{C}$ (for 4 days), $5^{\circ} \mathrm{C}$ (for 50 days) and finally to $2.5^{\circ} \mathrm{C}$ (for 50 days). They were brought back by keeping them at $15^{\circ} \mathrm{C}$ for 2 days before incubating them at $25 \pm 2^{\circ} \mathrm{C}$. In one of the experiments $48 \mathrm{~h}$ after fourth moult, the larvae were treated topically with a Juvenile Hormone analogue 'manta' (isopropyl 11-methoxy, 3,7,11trimethyl 2-4-dodecadienoate), in distilled water at $2 \mathrm{ppm}$. Larvae sprayed with distilled water were used as controls. Fat body, midgut and silk gland were used for the assay of glutamine synthetase activity. A $20 \%$ (w/v) homogenates of the eggs and the tissues were prepared in cold distilled water using a Potter-Elvehjem homogenizer. The homogenates were centrifuged at $3000 \mathrm{~g}$ at $4^{\circ} \mathrm{C}$ for $10 \mathrm{~min}$ and the infranatant was used as an enzyme source. The gluta- 
mine synthetase (EC 6.3.1.2) activity was determined following the method of Rowe et al. (1970). The reaction mixture contained $0.33 \mathrm{M}$ Imidazole- $\mathrm{HCl}$ buffer of $\mathrm{pH}$ $7.2, \quad 0.13 \mathrm{M} \quad \mathrm{MgCl}_{2}, 0.16 \mathrm{M}$ 2-mercaptoethanol, $0.66 \mathrm{~m}$ hydroxylamine $-\mathrm{HCl}$ adjusted to $\mathrm{pH} 7.2,0.33 \mathrm{M}$ sodium L-glutamate and $0.065 \mathrm{M}$ sodium salt of ATP. Protein content was determined according to Lowry et al. (1951) using bovine serum albumin standards.

\section{Results}

\section{L-Glutamine synthetase activity in embryonic development}

Glutamine synthetase activity was found after oviposition in acid-treated, chilled, diapause eggs at $0 \mathrm{~h}$ but not in non-diapause eggs and an initial increase in activity was observed in all except the chilled eggs (Fig. 1). Further, in non-diapause eggs after the initial rise over $24 \mathrm{~h}$ the activity remained unchanged till $72 \mathrm{~h}$ of development, then it increased in the latter part of development to a maximum in newly hatched larvae. On the other hand, the diapause eggs exhibited a slight and gradual increase in enzymatic activity up to $96 \mathrm{~h}$ with little significant change thereafter. In diapause eggs, the glutamine synthetase resembled

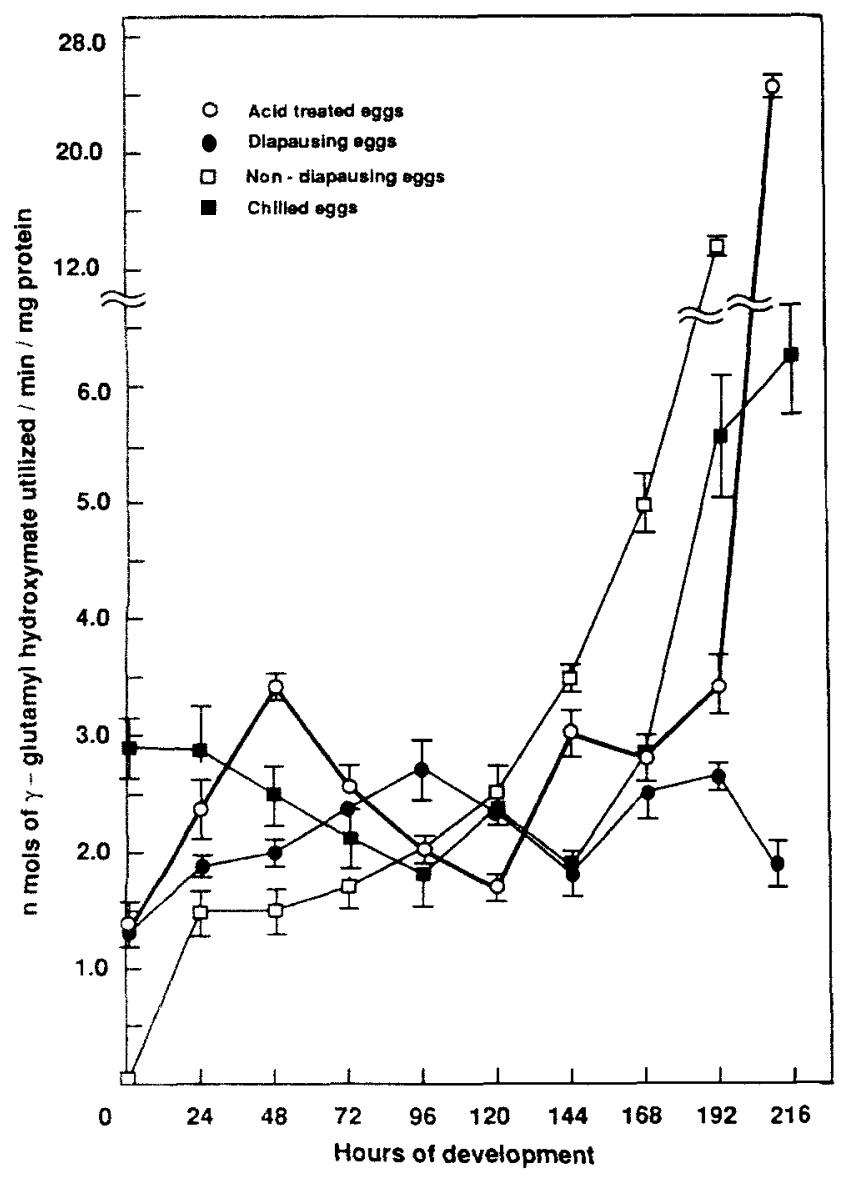

Fig. 1. L-Glutamine synthetase activity in the developing eggs of Bombyx mori. Values are mean $\pm \mathrm{SD}(n=6)$.
ALAT, AAT and GLDH in its activity pattern (data not included). In chilled eggs unlike the other types of eggs, the activity was relatively high at $0 \mathrm{~h}$ after the break of diapause. Contrary to the other types observed, a gradual decrease was noted in glutamine synthetase activity till $168 \mathrm{~h}$ with a marginal increase at $120 \mathrm{~h}$. Even the newly hatched larvae from chilled eggs showed a 2 times lesser activity than that of acid-treated eggs (Fig. 1). Acid treatment induced higher glutamine synthetase activity at later hours of development when compared to diapausing eggs. Increased activity was observed up to $48 \mathrm{~h}$ and later towards the end of embryonic development. It is obvious that during active organogenesis elevated levels of glutamine synthetase activity (Fig. 1) were observed.

\section{L-Glutamine synthetase activity in adult larvae and during} extended larval period

Glutamine synthetase activity was not detected in midgut tissue of larvae.

In the bivoltine (diapause) race when compared with the multivoltine (non-diapause) race the glutamine synthetase activity in the fat body was higher. The enzymic activity was undectable in silk gland of either race soon after fourth moult. The maximum activity was noted in silk gland on day 6 in multivoltine race and days 4 and 6 in the bivoltine race in the fifth stadium. Low levels of activity were observed on the day of spinning in silk gland of bivol-

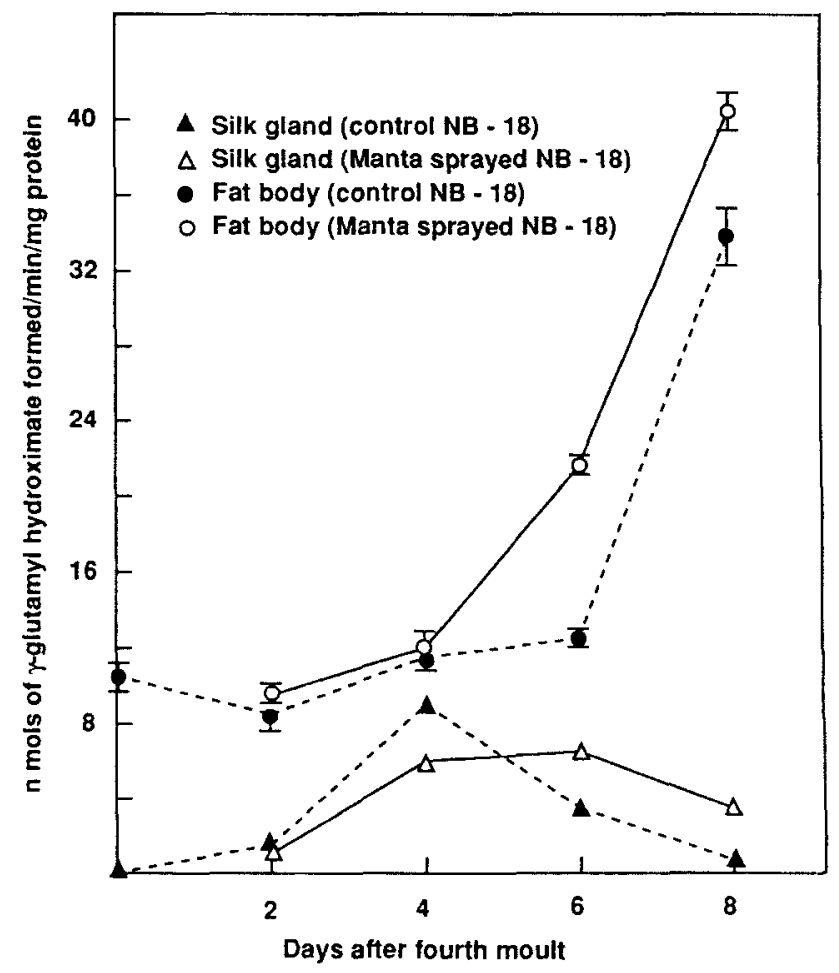

Fig. 2. The effect of $\mathrm{JH}$ analogue application on glutamine synthetase activity in whole tissues of developing fifth instar larvae of a bivoltine race of Bombyx mori. Values are mean $\pm \mathrm{SD}(n=6)$. 
Table 1. Glutamine synthetase activity (mean $\pm S D, n=6$ ) in the tissues of developing fifth instar larvae of bivoltine and multivoltine races of Bombyx mori.

\begin{tabular}{lcclll}
\hline & \multicolumn{2}{l}{ Posterior silk gland } & \multicolumn{2}{l}{ Fat body } \\
\cline { 2 - 3 } \cline { 5 - 6 } $\begin{array}{l}\text { Days in fifth } \\
\text { stadium }\end{array}$ & Bivoltine & $\begin{array}{l}\text { Multi- } \\
\text { voltine }\end{array}$ & & Bivoltine & $\begin{array}{l}\text { Multi- } \\
\text { voltine }\end{array}$ \\
\hline 0 & 0.00 & 0.00 & $13.99 \pm 0.93$ & $7.45 \pm 0.96$ \\
2nd & $7.74 \pm 1.72$ & $1.98 \pm 0.43$ & & $22.21 \pm 1.22$ & $25.42 \pm 1.8$ \\
4th & $143.75 \pm 6.29$ & $97.49 \pm 4.08$ & & $51.22 \pm 3.77$ & $75.02 \pm 1.71$ \\
6th & $136.56 \pm 7.40$ & $198.9 \pm 9.88$ & & $167.70 \pm 6.99$ & $131.90 \pm 6.98$ \\
8th & $32.53 \pm 11.38$ & $17.89 \pm 6.26$ & $335.29 \pm 12.53$ & $153.95 \pm 9.82$ \\
9th & - & 0.00 & - & $87.75 \pm 17.73$ \\
\hline
\end{tabular}

Units : nmol of $\gamma$-glutamyl hydroxymate formed in whole posterior silk gland and fat body per animal.

tine race. In fat body of bivoltine race a gradual increase in the glutamine synthetase activity was observed from day 0 . of the last stadium upto the day of spinning (Table 1).

The topical application of 'manta' attempted on the bivoltine race only. It resulted in extending the larval duration by 1 day. In untreated larvae the glutamine synthetase activity was high in silk gland on day 4 . The manta application reduced the glutamine synthetase activity on day 4 but in the latter part of development the activity was higher than in controls (Fig. 2); however, the overall pattern is similar.

\section{Discussion}

In the present study glutamine synthetase was found to be low during diapause, but whether the observed low activity is due to inhibition or due to repression of synthesis of enzyme is not known. Glutamine levels are low during diapause when compared with non-diapause eggs (Suzuki et al., 1984).

During diapause, because of the physiologically inactive state of the embryo, there will be a low demand for glutamine. Kurata et al. $(1980 \mathrm{a}, \mathrm{b})$ have shown that DNA and RNA synthesis are inactive during diapause. Because histogenesis is suspended until the break of diapause, the involvement of glutamine in protein synthesis is ruled out. Probably all these factors may contribute to the low glutamine synthetase activity during diapause recorded in the present study. In the early stages of diapause silkworm eggs show a gradual increase in glutamine synthetase activity till $96 \mathrm{~h}$. This initial high activity could be due to greater demand of glutamine for the synthesis of FAA, which accumulate in large quantities in diapause eggs (Suzuki et al., 1984). The higher glutamine synthetase activity in artificially treated and non-diapause eggs indicates the involvement of glutamine synthetase in several pathways as mentioned earlier. The glutamine synthetase activity as reported in the present investigation is much higher in the newly hatched larvae. There are at least two possible reasons for this: glutamine is involved in the synthesis of cuticular proteins (Chen, 1962); or the levels of free glutamine in the haemolymph of silkworm are very high, especially just prior to or after ecdysis (Gamo \& Kuroda, 1978).

In silkworm, the glutamine synthetase plays an important role in the efficient fixation and utilization of ammonia through L-glutamine:2-oxoglutarate amino transferase (GOGAT), and probably by donating its amide group to aspartic acid in amino acid synthesis through the Lasparagine:2-oxoglutarate amino transferase (AOGAT) pathway.

Fat body might be functional in channelling glutamine into haemolymph and it has been reported that in Prodenia eridania the fat body secretes glutamine into haemolymph (Levenbook, 1962). The glutamine requirements for the synthesis of silk protein amino acids may be derived from haemolymph, because the removal of the gland resulted in accumulation of glutamine in larval haemolymph (Wyatt, 1961). On topical application 'Manta' did not alter the glutamine synthetase activity of fat body significantly in freshly moulted larvae, whereas it increased it in mature larvae. This higher glutamine synthetase activity of fat body may also contribute to the elevation of FAA and protein levels in haemolymph. In vertebrates, glutamine synthetase synthesis is regulated by hydrocortisone (Moscana, 1973) and brings about the synthesis of RNA (Stryer, 1981). Both cortisone and JH act on the nuclei (Shigematsu, 1978; Stryer, 1981). Application of JH analogue resulted in reduction of glutamine synthetase activity in silk gland initially, but later it remained at a higher level. In silk glands, $\mathrm{JH}$ analogue brings about inhibition of RNA, DNA and protein synthesis. However, the inhibition is temporary and reversible (Shigematsu, 1978). It can be presumed that there must be an inhibition of glutamine synthetase breakdown and hence in the later part of development the hormone treated larvae have a higher glutamine synthetase activity in silk glands. The fat body, on the other hand, shows a higher activity. The $\mathrm{JH}$ analogue accelerates the synthesis of macromolecules in the fat body and consequently the related and responsible enzymes show greater activity. As glutamine is required for nucleic 
acid and other synthetic reactions, the glutamine synthetase activity necessarily could increase in the fat body.

\section{References}

Chen, P.S. (1962) Free amino acids in insects. Amino Acid Pools (ed. by J. H. Holden), pp. 115-135. Elsevier, Amsterdam.

Crone-Gloor, U.V. (1959) Quantitative Untersuchung der freien Aminosäuren and Polypeptide während der Embryonalentwicklung von Drosophila melanogaster. Journal of Insect Physiology, 3, 50-56.

Fukuda, T., Duchateau-Bosson, G.H. \& Florkin, M. (1961) Contributions to silkworm biochemistry. XXIV. Breakdown and biosynthesis of amino acids during the development of Bombyx mori L. Archives Internationales de Physiologie et de Biochimie, 69, 701-719.

Gamo, T. \& Kuroda, S. (1978) Quantitative changes of asparagine and glutamine in haemolymph of the silkworm Bombyx mori, during larval and pupal development. Applied Entomological Zoology, 13,223-226.

Gilmour. D. (1965) The Biochemistry of Insects. Academic Press, New York.

Kurata, S., Hamada, N., Saito, A., Koga, K. \& Sakaguchi, B. (1980a) Dissociability of ribosomes in high salt buffer in relation to diapause of Bombyx eggs. Journal of Sericulture Sciences, 49. $67-72$

Kurata, S., Yaginuma, T., Kobayashi, M., Koga, K. \& Sakaguchi, B. (1980b) DNA content and cell number during embryogenesis of Bombyx mori. Journal of Sericulture Sciences, 49, 107-110.

Lemnie, R.W. \& Birt, L.M. (1965) The localisation of particalbound tyrosine activating enzyme in Lucilla cuprina and the distribution of free amino acids during the life cycle. Journal of Insect Physiology. 11, 1213-1224.

Levenbook. L. (1962) The distribution of free amino acids, glutamine and glutamate in the southern armyworm Prodenia eridania. Journal of Insect Physiology, 8, 559-567.

Lowry, O.H., Rosenbrough, N.J., Farr, A.L. \& Randall, R.J. (1951) Protein measurement with Folin-Phenol reagent. Journal of Biological Chemistry, 193, 265-275.

MacFarlane, J.R. \& Hogan. T.W. (1966) Free amino acid changes associated with diapause in the eggs of the field cricket, Teleogrillus. Journal of Insect Physiology, 12, 1265-1278.

Mansing, A. (1967) Changes in the free amino acids of the haemolymph of Antheraea pernyi during induction and termination of diapause. Journal of Insect Physiology, 13, 1645-1655.

Moscona, A.A. (1973) Induction of glutamine synthetase in embryonic neuronal retina. A model for the regulation of specific gene expression n embryonic cells. Biochemistry of Cell Differentiation, Vol. 24 (ed. by A. Monroy and R. Tsanev), pp. 1-23. Academic Press, London.

Osanai, M. \& Yonezawa, Y. (1986) Changes in amino acid pools in the silkworm, Bombyx mori during embryonic life. Alanine accumulation and its conversion to proline during diapause. Insect Biochemistry, 16, 171-179.

Rowe, W.B., Ronzio, A.R., Vaira, P.W. \& Meister, A. (1970) Glutamine synthetase (sheep brain). Methods in Enzymology. XVIII, Part A (ed. by H. Tabor and C. W. Tabor), pp. 900-910. Acadernic Press, London.

Shigematsu, H. (1978) The nature of juvenoid effects on growth and changes of proteins, amino acid and nucleic acid content in silkworm Bombyx mori on application of excessive dose. Journal of Sericulture Sciences, Japan, 47, 292-300.

Stadtman, E.R. (1973) A note on the significance of glutamine in intermediary metabolism. The Enzymes of Glutamine Metabolism (ed. by S. Prusiner and E. R. Stadtman), pp. 1-6. Academic Press, New York.

Storey, K.B., Baust, J.G. \& Storey, J.M. (1981) Intermediary metabolism during low temperature acclimation in the overwintering gall fly larva, Eurosta solidoginis. Journal of Comparative Physiology, 144, 183-190.

Stryer, L. (1981) Biochemistry. W. H. Freeman and Company, San Francisco.

Suzuki, K., Hosaka, M. \& Miya, K. (1984) The amino acid pool of Bombyx mori eggs during diapause. Insect Biochemistry, 14, $557-561$.

Ullal, S.R. \& Narasimanna, M.N. (1981) Handbook of Practical Sericulture. Central Silk Board, Bombay.

Wyatt, G.R. (1961) The biochemistry of insect haemolymph. Annual Review of Entomology, 6, 75-102.

Accepted 7 November 1991 